\title{
Dopa responsive dystonia: a treatable condition misdiagnosed as cerebral palsy
}

\author{
Kathryn Boyd, Victor Patterson
}

Patients thought to have cerebral palsy may instead have dopa responsive dystonia
We report on two young women who were severely disabled for 10 years and finally confined to wheelchairs before their neurological disorders were diagnosed and cured by levodopa.

\section{Case 1}

The patient developed normally until she was 5 years old, when difficulty in walking was noted. At first this was intermittent and characterised by sudden walking on tiptoe with arching of the back. This resulted in frequent falls. Cerebral palsy was diagnosed. The disorder progressed slowly. At 9 years old she was no longer able to run. Episodes of sudden akinesia became troublesome, and she often walked unsteadily on tiptoe. At age 11 she was sent to a school for disabled children. At 16 she needed the support of two people to walk a short distance. At 17 she stood and walked permanently on tiptoe. Before presentation at 18 she had been confined to a wheelchair for six months.

Over the years her arms and hands had become stiff and they trembled at times. By the age of 15 she could no longer use a dinner knife. She wrote slowly and barely legibly. Her symptoms became worse as the day progressed. There was no known history of motor disorder in her family.

On examination at age 18 her mental state was normal; she was emotionally labile; her speech was slow; and she had few facial expressions, her voluntary facial movements being slow and stiff and her smile vacant. When she sat at rest her posture was abnormal; her fingers showed bilateral flexion dystonia, her ankles showed plantar flexion, and her neck showed extension. On standing she rose slowly to the tiptoe position with flexion at the hips and knees. She was considerably unstable when sitting and standing. With the support of two people she could take a few slow steps stiffly on tiptoe. Turning manoeuvres were difficult. Her severe bradykinesia was demonstrated well when she attempted repetitive tasks such as touching her finger with her thumb.

Increased tone and cogwheeling were present in both arms and legs. There was no contracture of tendons, and muscle power was normal. There was generalised hyperreflexia, and plantar responses were extensor. The cranial nerves were normal. Fundi were normal and Kayser-Fleischer rings absent. General examination gave normal results. Extensive neurological investigations were performed, and all of the following were found to be normal: serum copper and caeruloplasmin concentrations; urinary copper excretion before and after challenge with penicillamine; electroencephalograms; computed tomograms of the skull; visual and sensory evoked responses; electroretinograms; and peripheral nerve conduction. Routine haematological and biochemical tests of renal and hepatic function also gave normal results.

She was given Sinemet-110 (levodopa $100 \mathrm{mg}$, carbidopa $10 \mathrm{mg}$ ) half a tablet three times daily. Within three days her muscle tone was normal and after one week she was walking unsupported. After one month her gait was minimally stiff and she was running and dancing. Manual dexterity was normal. Examination showed normal tone, mild postural instability, and mild chorea of the arms and legs. She complained of nausea. The dose of the drug was reduced to a quarter of a tablet twice daily. Three years later she remained well taking this dose and led an entirely normal life.

\section{Case 2}

The patient developed normally until she was 5 years old, when she started to walk on the toes of her left foot and developed an intention tremor in her left hand. Mild spastic paraplegia was diagnosed. Three years later the symptoms were more severe and progressive spastic paraplegia was diagnosed. At age 11 she was walking so unsteadily that she needed help to take even one step. She started to use a wheelchair and was sent to a school for disabled children. At this stage she found it difficult to write. There was a family history of spasmodic torticollis affecting her maternal grandmother, mother, and sister.

Her symptoms continued to worsen, and dystonia musculorum deformans was suspected. When she was 17 Sinemet-110 was prescribed. Her symptoms improved within days, and after three months she was walking independently.

She was examined when she was 30 and had been taking levodopa for 13 years with sustained benefit and with no adverse effect. She felt well and was leading a normal life. Slight scoliosis in the lumbar region was noted. There was minimal postural instability when sitting and occasional minimal chorea of her outstretched hands. Her plantar responses were flexor. Further examination gave normal results.

\section{Discussion}

Both patients had progressive problems with walking that started at the age of 5. The findings of dystonia with cogwheel rigidity and bradykinesia and the dramatic response to levodopa confirmed the diagnosis of dopa responsive dystonia. ${ }^{1}$ This condition, also known as hereditary dystonia parkinsonism syndrome of juvenile onset, familial generalised dystonia with diurnal fluctuation, progressive dystonia with marked diurnal fluctuation, and hereditary progressive dystonia with marked diurnal fluctuation, was first described by Segawa $e t a l^{2}$ and recently reviewed by Nygaard and Duvoisin. ${ }^{23}$ Eighty six cases have been reported. Because the disorder has a high familial incidence it is considered to be hereditary, but the mode of inheritance is not known.

In two thirds of cases the onset has occurred between the ages of 4 and 8 . Half the children have presented with a gait disorder due to dystonia. Parkinsonian features are seen at the first examination in only one fifth of the cases. In some cases the symptoms show diurnal fluctuation, ${ }^{45}$ but, although present, this was by no means pronounced in our two patients. In every case there is a dramatic and sustained response to treatment with levodopa. The effect does not depend 
on the degree of disability at the time of diagnosis and does not seem to wear off with time.

A recent study showed that five patients with dopa responsive dystonia had cerebrospinal fluid concentrations of homovanillic acid, 5-hydroxyindoleacetic acid, and biopterin that were below the normal range. ${ }^{6}$ The deficiency of biopterin in patients with diurnally fluctuating dystonia was significantly greater than the deficiency in patients with diurnally stable dystonia. The association between dopa responsive dystonia and a deficiency of biopterin can be explained by the fact that reduced biopterin is an essential cofactor for tyrosine hydroxylase, the enzyme that is rate limiting in the synthesis of catecholamines and serotonin.

We were able to find only one necropsy report of a patient with dopa responsive dystonia. ${ }^{7}$ The cells of the substantia nigra were round and poorly pigmented like infant cells, suggesting a maturational defect rather than a degenerative problem.

Both of our patients were initially misdiagnosed as having cerebral palsy. This is understandable because hyperreflexia, extensor plantar responses, and muscle stiffness occur in cerebral palsy and dopa responsive dystonia. The onset after birth, the progressive course, and the Parkinsonian features of the disease in these patients, however, are not typical of cerebral palsy.
At present awareness of dopa responsive dystonia seems to be confined to specialists in movement disorders. Unfortunately, these are not the people who look after most of the patients with cerebral palsy, and almost certainly many cases of this type of dystonia are not diagnosed. There are few conditions in which a small dose of a drug can restore a wheelchair bound disabled person to normality. Dopa responsive dystonia needs to be recognised by general practitioners, paediatricians, orthopaedic surgeons, and indeed all doctors responsible for caring for patients with cerebral palsy.

1 Nygaard TG, Marsden CD, Duvoisin RC. Dopa-responsive dystonia. Ad Neurol 1988;50:377-84

2 Segawa M, Hosaka A, Miyagawa F, Nomura Y, Imai H. Hereditary progressiv dystonia with marked diurnal fluctuation. Adv Neurol 1976;14:215-33.

3 Nygaard TG, Duvoisin RC. Hereditary dystonia-parkinsonism syndrome of juvenile onset. Neurology 1986;36:1424-8.

4 Ouvrier RA. Progressive dystonia with marked diurnal fluctuation. Ann Neurol 1978;4:412-7.

5 Segawa $M$, Nomura $Y$, Kase $M$. Diurnally fluctuating hereditary progressive dystonia. In: Vinken PJ, Bruyn GW, Klawaris HL, eds. Handbook of clinical neurology. Vol 5. Amsterdam: Elsevier Science, 1988:529-39.

6 Fink JM, Barton N, Cohen W, Lovenberg W, Burns RS, Hallett M. Dystonia with marked diurnal variation associated with biopterin deficiency. Neurology 1988;38:707-11.

7 Yokochi M, Narabayashi H, Iizuku R, Nagatsu T. Juvenile parkinsonism some clinical, pharmacological and neuropathological aspects. Adv Neurol
1984;40:407-13.

(Accepted 6 fanuary 1989
This article and the interview with Walter Van't Hoff are the thirteenth and fourteenth in a series on the white paper Working for Patients and its accompanying working papers. The series started on 18 February (p 437).

Department of Medicine, St George's Hospital Medical School, London SW17 0RE

P H Millard, FRCP, Eleanor Peel professor of geriatric medicine

P Higgs, PHD, research fellow P Rochon, FRCPCAN, honorary lecturer, supported by the Royal Canadian Legion

Correspondence to: Professor Millard.

BrMed f 1989;298:1020-1

\title{
NHS Review
}

\section{Aging: Should it be left to chance?}

\author{
P H Millard, P Higgs, P Rochon
}

The government created the specialty of geriatric medicine within a national health service and the government is now destroying it. The specialty was created as a solution to misdiagnosis, mismanagement, absent teamwork, and lack of rehabilitation in local government run infirmaries. As a service of last resort geriatric medicine developed into a medical subspecialty concerned with the clinical, preventive, remedial, and social aspects of health and disease in elderly patients. It would be a disaster for the aged if our government, while introducing one American economist's dream, made the health care of the aged poor as bad as that provided in the country from which the fiscal dream emerged.' Certainly proposals on the care of the elderly are conspicuous by their absence from the white paper, ${ }^{2}$ and by failing to respond to $\mathrm{Sir}$ Roy Griffiths's report on community care the government shows its indifference to integrated planning for acute and chronic care.

In 1981 the government thought that it could no longer afford the specialty of geriatric medicine and turned to integration with general medicine instead. Some doctors argued that there was no organ system or procedure that justified the specialty's presence. ${ }^{4} \mathrm{Sir}$ Roy Griffiths considered that hospitals' responsibilities should cease at rehabilitation, and many managers, thinking of cost implications, support his view and are shedding responsibility for long stay care on to nursing homes. $^{3}$

Those who want hospital consultants to shed any responsibility for long stay care fail to realise that responsibility not interest drives the wheel of rehabilitation. Consultants in geriatric medicine have clinical responsibility for the long term hospital care of patients in their catchment areas. They respond to this by developing strategies of care based on inpatient re- habilitation, day hospital provision, and coordinated aftercare. Theirs is a success story which our country should support.

\section{. . . basic to success is cooperation with other specialties not the erection of defensive boundaries.}

\section{Cooperation is basic to success}

Illness presents differently in old age. Multiple pathology is the rule rather than the exception. Basic to success in caring for the elderly is cooperation with other specialties not the erection of defensive boundaries. In the United States the Institute of Medicine recognises the need for leadership by physicians in geriatric medicine because care of the elderly is complex and requires specialised knowledge.

Between 1986 and 1996 the number of people aged over 85 will grow by nearly a half; the over 85 s have increased from 459000 in 1976 to 603000 today and will be 894000 in 1996. This older group spends more days in hospital and uses a disproportionate amount of the health care budget. ${ }^{5}$ Ignore their needs for specialist medical services and the whole house of cards collapses.

Plans to shorten patients' length of stay and to develop outpatient medical services may work for young people living with families but for the aged it is a non-starter. The over $85 \mathrm{~s}$ are more likely to be single or widowed, to live alone, to be in substandard accommodation, and have income levels at or below the poverty line. To send such people home sicker and 